\title{
VALIDATION AND UPSCALING OF SOIL MOISTURE SATELLITE PRODUCTS IN ROMANIA
}

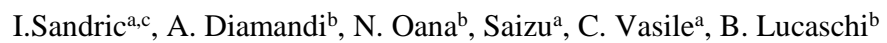 \\ a Esri Romania, Bucharest, Romania - isandric@esriro.ro, cvasile@esriro.ro,dsaizu@esriro.ro \\ b National Meteorological Administration, Bucharest, Romania - diamandi@meteoromania.ro, oana.nicola@meteoromania.ro, \\ bogdan.lucaschi@meteoromania.ro \\ ${ }^{\mathrm{c}}$ University of Bucharest, Faculty of Geography, Romania - ionut.sandric@ geo.unibuc.ro
}

\section{Commission II, WG II/4}

KEY WORDS: SMOS, soil moisture, validation, Romania

\begin{abstract}
:
The study presents the validation of SMOS soil moisture satellite products for Romania. The validation was performed with in-situ measurements spatially distributed over the country and with in-situ measurements concentrated in on small area. For country level a number of 20 stations from the national meteorological observations network in Romania were selected. These stations have in-situ measurements for soil moisture in the first $5 \mathrm{~cm}$ of the soil surface. The stations are more or less distributed in one pixel of SMOS, but it has the advantage that covers almost all the country with a wide range of environmental conditions. Additionally 10 mobile soil moisture measurements stations were acquired and installed. These are spatially concentrated in one SMOS pixel in order to have a more detailed validation against the soil type, soil texture, land surface temperature and vegetation type inside one pixel. The results were compared and analyzed for each day, week, season, soil type, and soil texture and vegetation type. Minimum, maximum, mean and standard deviation were extracted and analyzed for each validation criteria and a hierarchy of those were performed. An upscaling method based on the relations between soil moisture, land surface temperature and vegetation indices was tested and implemented. The study was financed by the Romanian Space Agency within the framework of ASSIMO project http://assimo.meteoromania.ro
\end{abstract}

\section{INTRODUCTION}

Soil moisture is a pivotal variable in land surface, atmosphere, hydrological and climate models. Moreover, with the changing climate there is a need for long term spatially distributed soil moisture data. Spaceborne microwave remote sensing has proven to be a valuable tool to fulfil those needs by quantitatively measuring soil moisture on a global scale under a variety of conditions (Clement Albergel et al., 2012; Clément Albergel et al., 2011; Dorigo et al., 2015; Draper et al., 2013; Louvet et al., 2015; Panciera et al., 2009; Petropoulos, Ireland, \& Barrett, 2015; Petropoulos, Ireland, \& Srivastava, 2015; Pierdicca et al., 2015; Piles, Petropoulos, Sánchez, GonzálezZamora, \& Ireland, 2016; Rossato, De Jeu, Alvalá, \& Souza, 2011) It monitors soil moisture on a spatial and temporal scale, which cannot be achieved with in situ sampling. However, soil moisture is highly variable in both space and time as a result of heterogeneity in vegetation, soil properties, topography and climatic drivers. As a consequence, in situ soil moisture measurements play an important role in the calibration and validation of satellite-based soil moisture retrievals and landsurface models. However, in most cases soil moisture networks provide one single observation within a satellite footprint, which impedes the upscaling of in situ soil moisture to the footprint level.

In Romania, soil moisture data is available from the agrometeorological network with a temporal resolution of 10 days. Validation requires hourly in-situ measurements from a dense network, whose nodes locations have to observe a number of criteria. Therefore, it has been decided to complement observations at a 22 weather station locations with soil moisture and temperature measurements

\section{METHODS AND DATA}

There are a important number of papers that deals with MOS validation for the entire world(Clément Albergel et al., 2011; Al-Yaari, Wigneron, Ducharne, Kerr, Wagner, et al., 2014; Louvet et al., 2015; Pan et al., 2012; Petropoulos, Ireland, \& Barrett, 2015; Petropoulos, Ireland, \& Srivastava, 2015; Pierdicca et al., 2015; Scaini, Sanchez, Vicente-Serrano, \& Martinez-Fernandez, 2015; Wanders et al., 2012). Most of the papers are assessing the SMOS soil moisture by comparison with in-situ data. Some of them are using a small number of station spatially distributed in one SMOS pixel, but some of them are using at least 20 in-situ stations for soil moisture(Panciera et al., 2009; Scaini et al., 2015). The evaluation of SMOS soil moisture product was also performed against physically-based models (Wanders et al., 2012). Other studies have focused on downscaling SMOS soil moistures products using either deterministic (Merlin, WALKER, Chehbouni, \& Kerr, 2008) either by fitting a regression model between other vegetation products obtained from MODIS, SEVIRI etc and the SMOS soil moisture product (Piles et al., 2011, 2016; Yu, Di, \& Yang, 2008)

The approach presented in the current study was based on the evaluation of SMOS L2 and L3 soil moisture products over Romania using in-situ stations evenly distributed over the entire country and also ins-situ station concentrated in one SMOS pixel

The in-situ stations evenly distributed over Romania are part of the network for meteorological observations from The National 
Meteorological Administration of Romania. These are presented in Figure 1

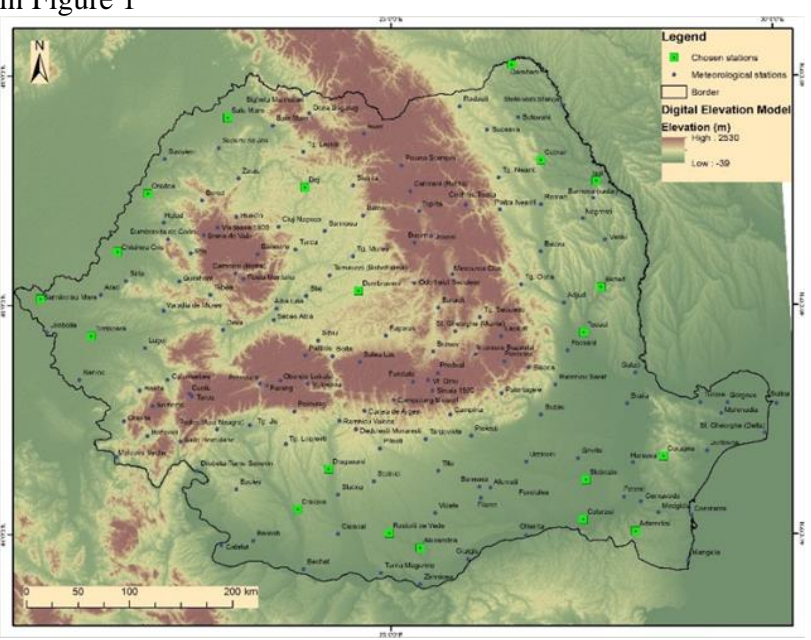

Figure 1 In-situ soil moisture station located in the existing weather stations

In order to select the most suitable locations of the in-situ soil moisture stations, the following criteria and information had been taken into consideration:

existing weather stations locations;

site elevation $<300-500 \mathrm{~m}$;

minimal forest, water and localities coverage;

small amount of argil soil;

reduced RFI interference

Eight SMOS pixels have been selected to be compared with insitu data. This selection was made in relation to the long row of in-situ data (more than 6 months)

The Corine Land Cover 2012 database was simplified in 6 categories: Artificial surfaces, Agriculture land, Pastures, Forests, Waters and Beaches, in order to express the best homogeneity of the soil moisture

The soil data was assembled in 5 texture classes according to the contained soil particles (sand, loam and clay). Other important issue of the texture classes is the water permeability. To find the most representative combination of topsoil $(0-5 \mathrm{~cm})$ and land cover types within the SMOS Level 2 pixel (across DGG node) this data will be reclassified. So, the composite classes will be a combination of the two variables, from the most favourable ones to the most unwanted

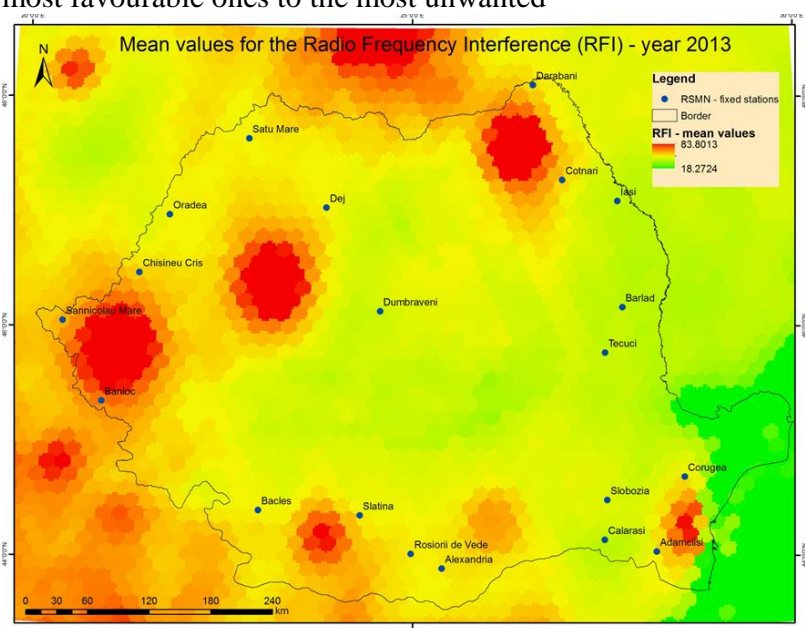

Figure 2 RFI mean values for the year 2013

An important aspect is related with the RFI interference (AlYaari, Wigneron, Ducharne, Kerr, de Rosnay, et al., 2014; Al-
Yaari, Wigneron, Ducharne, Kerr, Wagner, et al., 2014) In order to identify which are the most exposed areas from Romania, an assessment of the RFI values from SMOS imagery was performed. All the SMOS L2 images for Romania for the year 2013 were downloaded and statistically processed. Maximum, Minimum, Mean and Standard Deviation values for each pixel were calculated. Based on these images areas with high RFI values were excluded (Figure 2). These areas are located in the north, west and eastern part of Romania and correspond mostly with international airports. Small values are presented in the central-eastern part of the country and also in the southern part. The SMOS pixel was selected in areas with very small values of RFI for the year 2013

A number of 20 locations have been identified to correspond with the above criteria and these locations were selected to install in-situ soil moisture and temperature sensors

The in-situ Decagon 5TM sensors are connected to a data logger equipped with a data connection module. The schema for collecting and sending soil moisture and temperature values are presented in Figure 3
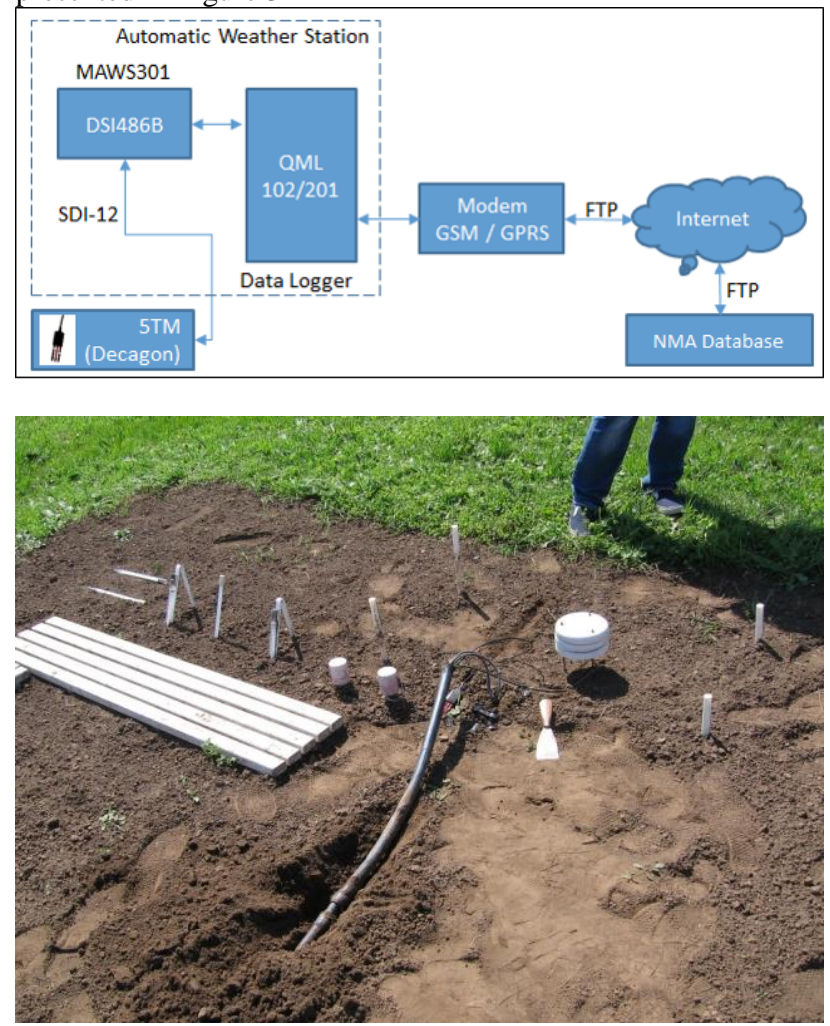

Figure 3 In-situ soil moisture and temperature station: a) schema; b) field example

The methodology used for SMOS validation was based on comparison of the mean daily value and spearman correlation coefficient between the SMOS L2 and L3 and the in-situ measurements at national scale and also concentrated in one pixel. The spearman correlation coefficient was selected because the soil moisture data didn't had a normal distribution. The normal distribution test was performed with Shapiro-Wilk test for normality

\section{RESULTS}

All the SMOS soil moisture products have been downloaded starting with 1th of January 2013. All the images have been intersected with the national and local in-situ soil moisture 
stations. Long time series have been obtained for each station. Periods of records are different because the installation of the stations was a lengthy process conducted over several months Test areas are spread evenly in main agricultural areas and spatially located near the village: Tecuci, Slatina, Calarasi, Corugea, Dumbraveni, Barlad, Bacles and red Vedas.

For each data set Shapiro-Wilk test was performed to verify if the data sets had a normal distribution. The results indicated a value of coefficient of statistical significance (p) less than 0.05 threshold indicating a different statistical distribution of the normal distribution. Following Shapiro-Wilk test result was selected Spearman correlation test to validate SMOS preliminary products

In the figure bellow are presented the location of in-situ measurements at national scale and for one SMOS pixel
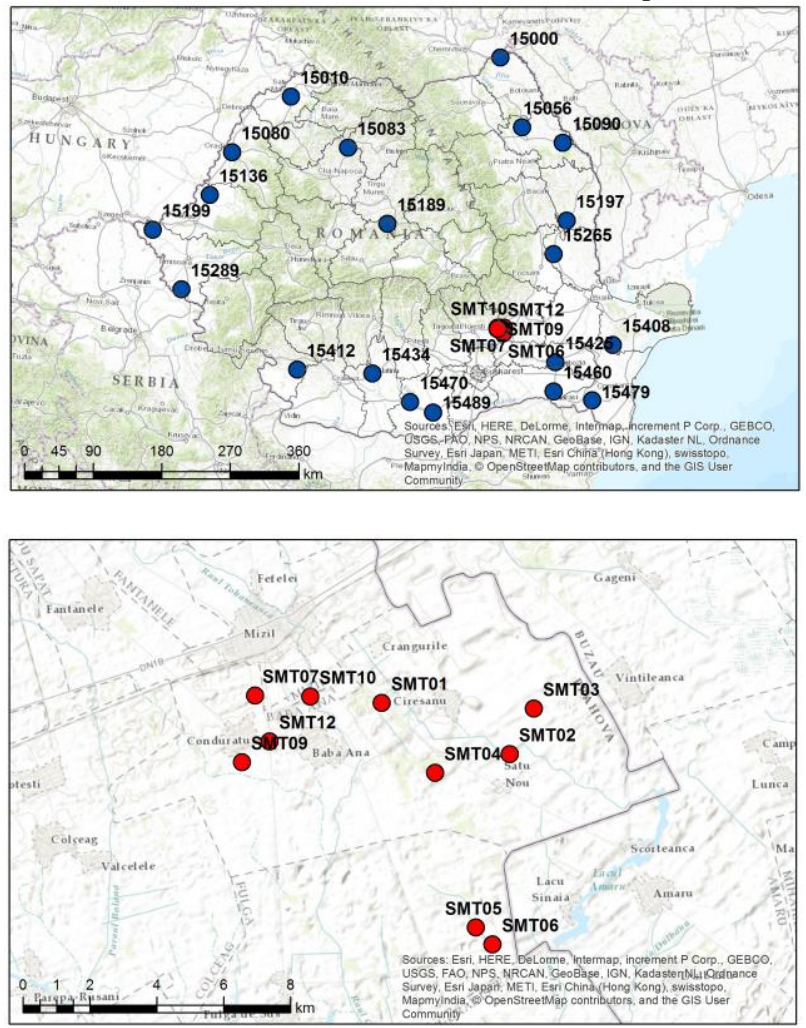

Figure 4 Locations for in-situ measurements at national scale and for one SMOS pixel

As expected, a large discrepancy can be noticed in every pixel, due to different scales (punctual in-situ measurements and 15 square $\mathrm{km}$ for satellite pixels) and also the high spatial variability of the soil moisture. The charts from the figure bellow clearly presents a very heterogeneous evolution os soil moisture by comparison of SMOS values with in-situ measurments

For most of the stations, SMOS soil moisture indicate significant under-/overestimation of the in-situ data (biases of $0.090 / 0.102 \mathrm{~m} 3 / \mathrm{m}-3$ ), while $\mathrm{R}^{2}$ is in the range of $0.00-0.31$, well below the worldwide validation results of the SMOS retrieved soil moisture $\mathrm{R}^{2}$ of 0.49

Overall an overestimation of soil moisture values is recorded by the SMOS SM L2 product

The same evolution is present at national level, with the SMOS L2 overestimation of soil moisture

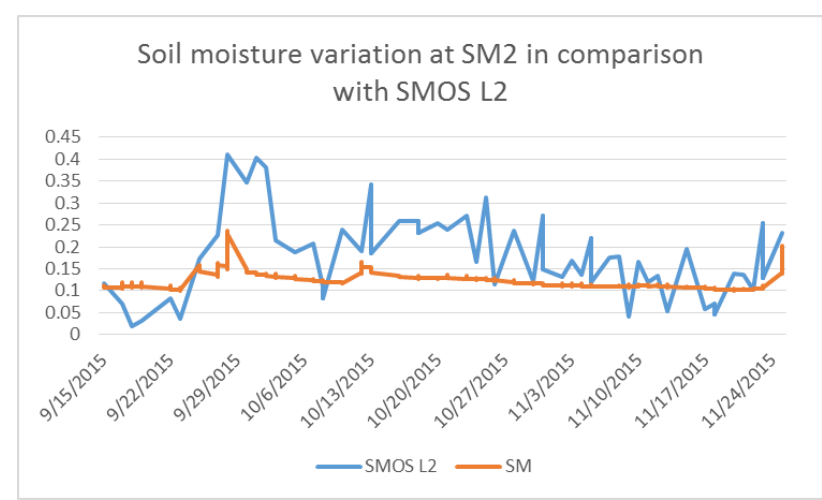

Soil moisture variation at SM3 in comparison with SMOS L2

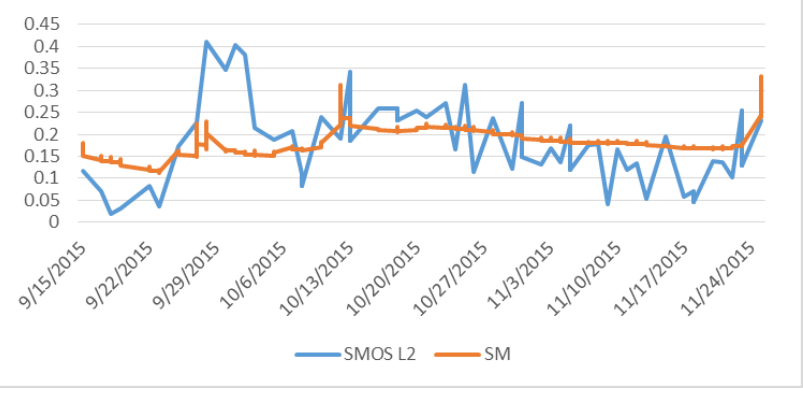

Soil moisture variation at SM5 in comparison with SMOS L2

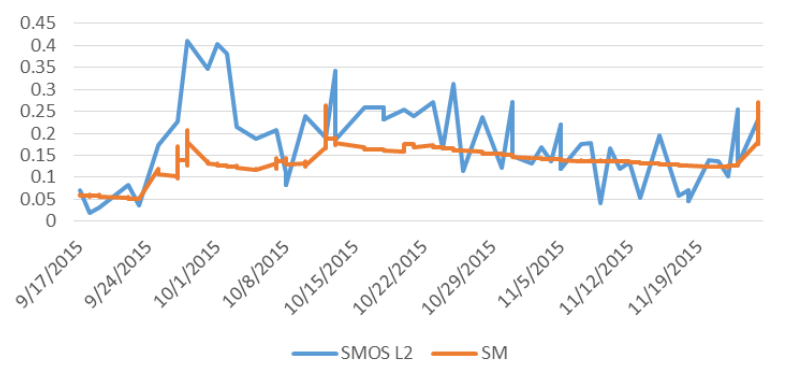

Soil moisture variation at SM6 in comparison with SMOS L2

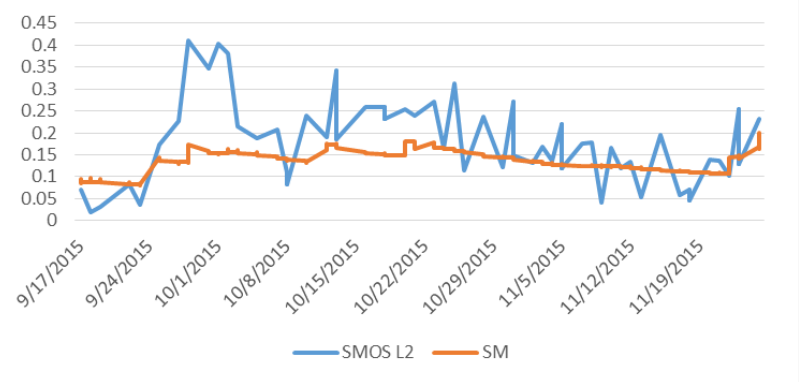




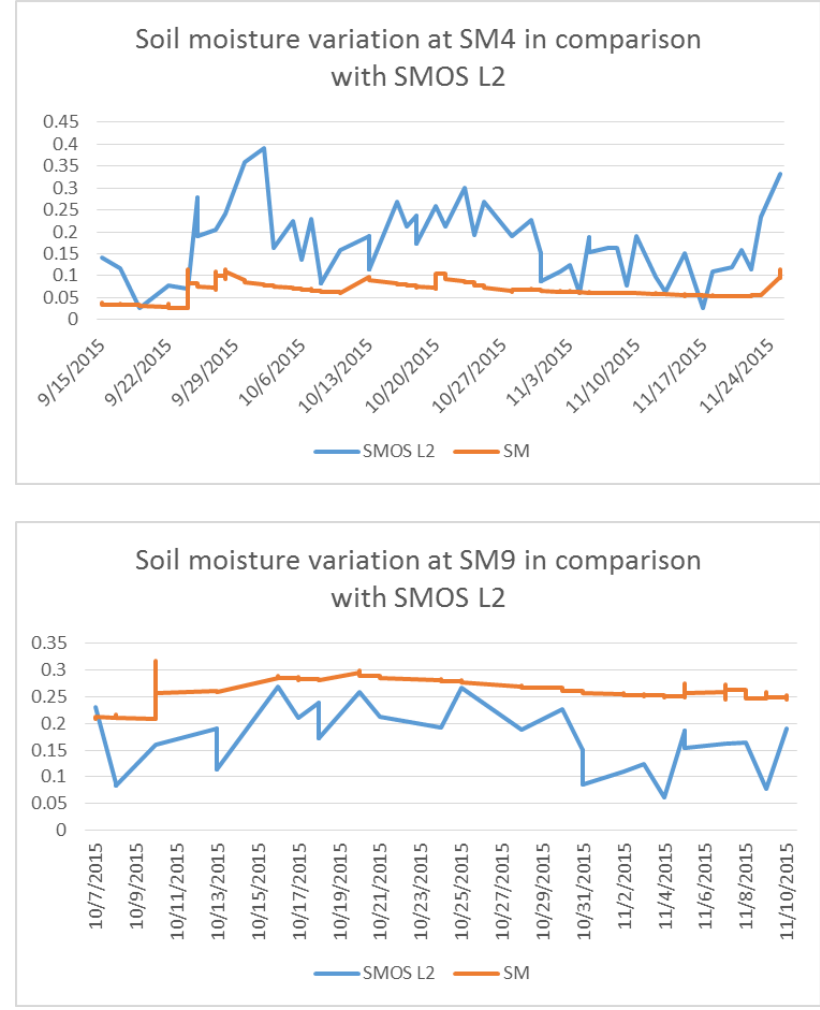

Soil moisture variation at SM10 in comparison with SMOS L2
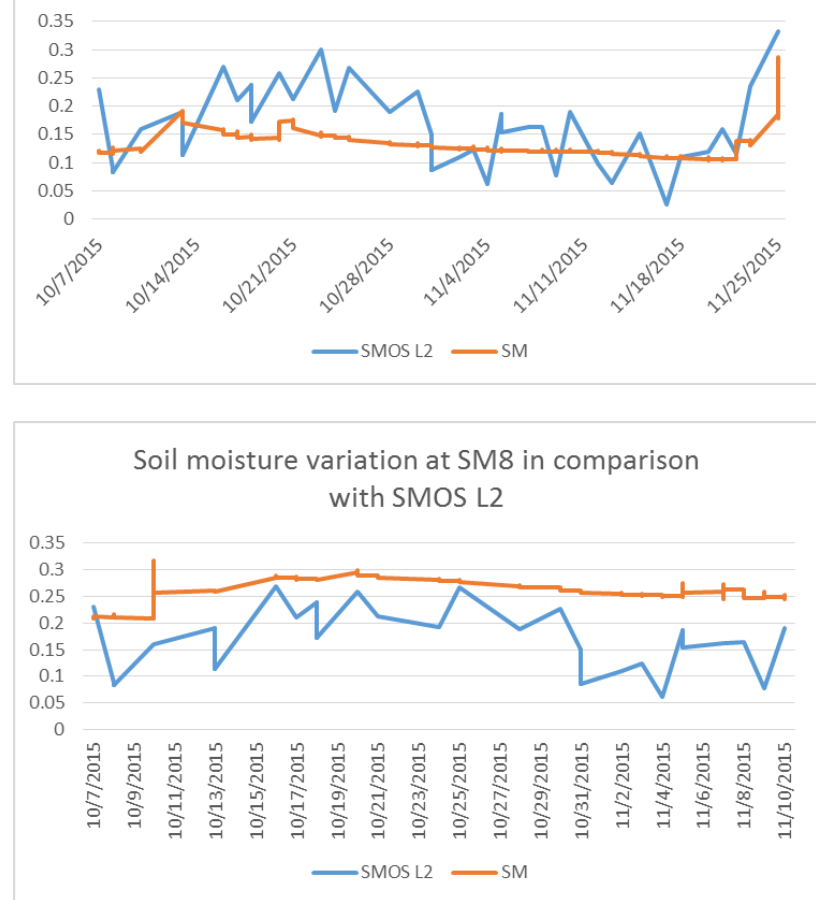

Figure 5 Soil moisture variation comparison for SMOS L2 and in-situ measurements for one SMOS pixel

At national level the same overestimation of soil moisture values is observed for most stations. The average value oscillates between values of $\sim 0.1 \mathrm{~mm}$. The absence of large standard deviation (Table 1) values encourages further statistics to identify a relationship between the values of soil moisture measured and extracted from SMOS

\begin{tabular}{|l|l|l|}
\hline National sm stations & Mean & STD \\
\hline Tecuci & -0.07 & 0.08226786 \\
\hline Slatina: & -0.06850859 & 0.08706535 \\
\hline Rosiorii de Vede: & -0.0660413 & 0.104461 \\
\hline Dumbraveni: & -0.02944656 & 0.07575896 \\
\hline Corugea: & -0.1294626 & 0.1113068 \\
\hline Calarasi: & -0.08429508 & 0.08872106 \\
\hline Barlad: & -0.07762334 & 0.08116432 \\
\hline Bacles: & 0.0793062 & 0.08244528 \\
\hline
\end{tabular}

Table 1 Mean and standard deviations for soil moisture differences values (SMOS - in-situ)

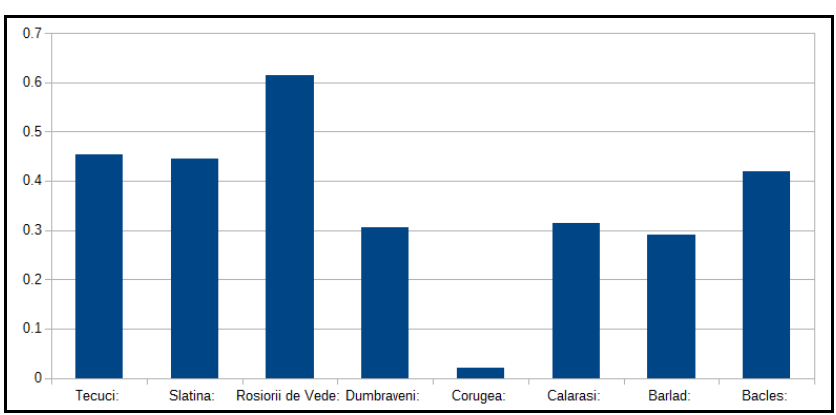

Figure 6 Spearman correlation coefficients

Figure 6 presents an average correlation coefficient of 0.35 and a standard deviation of 0.17 . The results indicate a correlation (less than 0.5) between the value of the SMOS soil moisture recorded and measured value, except Rosiorii station to see where the correlation value is greater than 0.5

\section{CONCLUSIONS}

This study is a preliminary phase towards the validation of the SMOS soil moisture product over temperate continental regions of Romania. Further assessment with data for more then one year is necessary in order to compensate for seasonal changes

\section{ACKNOWLEDGEMENTS (OPTIONAL)}

This work was supported by a grant of the Romanian National Authority for Scientific Research, Program for research- Space Technology and Advanced Research - STAR, project number 62/2013, Assessment of Satellite Derived Soil Moisture Products over Romania, http://assimo.meteoromania.ro

\section{REFERENCES}

Albergel, C., de Rosnay, P., Gruhier, C., Muñoz-Sabater, J., Hasenauer, S., Isaksen, L., ... Wagner, W. (2012). Evaluation of remotely sensed and modelled soil moisture products using global ground-based in situ observations. Remote Sensing of Environment, 118, 215226. http://doi.org/10.1016/j.rse.2011.11.017

Albergel, C., Zakharova, E., Calvet, J.-C., Zribi, M., Pardé, M., Wigneron, J.-P., ... Fritz, N.-D. (2011). A first assessment of the SMOS data in southwestern France using in situ and airborne soil moisture estimates: The CAROLS airborne campaign. Remote Sensing of Environment, 115(10), 2718-2728. http://doi.org/10.1016/j.rse.2011.06.012

Al-Yaari, A., Wigneron, J. P., Ducharne, A., Kerr, Y., de Rosnay, P., de Jeu, R., ... Mialon, A. (2014). Globalscale evaluation of two satellite-based passive microwave 
soil moisture datasets (SMOS and AMSR-E) with respect to Land Data Assimilation System estimates. Remote Sensing of Environment, 149, 181-195. http://doi.org/10.1016/j.rse.2014.04.006

Al-Yaari, A., Wigneron, J. P., Ducharne, A., Kerr, Y. H., Wagner, W., De Lannoy, G., ... Mialon, A. (2014). Global-scale comparison of passive (SMOS) and active (ASCAT) satellite based microwave soil moisture retrievals with soil moisture simulations (MERRA-Land). Remote Sensing of Environment, 152, 614-626. http://doi.org/10.1016/j.rse.2014.07.013

Dorigo, W. A., Gruber, A., De Jeu, R. A. M., Wagner, W., Stacke, T., Loew, A., ... Kidd, R. (2015). Evaluation of the ESA CCI soil moisture product using ground-based observations. Remote Sensing of Environment, 162, 380395. http://doi.org/10.1016/j.rse.2014.07.023

Draper, C., Reichle, R., de Jeu, R., Naeimi, V., Parinussa, R., \& Wagner, W. (2013). Estimating root mean square errors in remotely sensed soil moisture over continental scale domains. Remote Sensing of Environment, 137, 288-298. http://doi.org/10.1016/j.rse.2013.06.013

Louvet, S., Pellarin, T., al Bitar, A., Cappelaere, B., Galle, S., Grippa, M., ... de Rosnay, P. (2015). SMOS soil moisture product evaluation over West-Africa from local to regional scale. Remote Sensing of Environment, 156, 383-394. http://doi.org/10.1016/j.rse.2014.10.005

Merlin, O., WALKER, J. P., Chehbouni, A., \& Kerr, Y. (2008). Towards deterministic downscaling of SMOS soil moisture using MODIS derived soil evaporative efficiency. Remote Sensing of Environment, 112(10), 3935-3946. http://doi.org/10.1016/j.rse.2008.06.012

Pan, M., Sahoo, A. K., Wood, E. F., Al Bitar, A., Leroux, D., \& Kerr, Y. H. (2012). An Initial Assessment of SMOS Derived Soil Moisture over the Continental United States. IEEE Journal of Selected Topics in Applied Earth Observations and Remote Sensing, 5(5), 1448-1457. http://doi.org/10.1109/JSTARS.2012.2194477

Panciera, R., Walker, J. P., Kalma, J. D., Kim, E. J., Saleh, K., \& Wigneron, J.-P. (2009). Evaluation of the SMOS LMEB passive microwave soil moisture retrieval algorithm. Remote Sensing of Environment, 113(2), 435444. http://doi.org/10.1016/j.rse.2008.10.010

Petropoulos, G. P., Ireland, G., \& Barrett, B. (2015). Surface soil moisture retrievals from remote sensing: Current status, products \& future trends. Physics and Chemistry of the Earth, Parts $A / B / C, \quad 83-84, \quad 36-56$. http://doi.org/10.1016/j.pce.2015.02.009

Petropoulos, G. P., Ireland, G., \& Srivastava, P. K. (2015). Evaluation of the Soil Moisture Operational Estimates From SMOS in Europe: Results Over Diverse Ecosystems. IEEE Sensors Journal, 15(9), 5243-5251. http://doi.org/10.1109/JSEN.2015.2427657

Pierdicca, N., Fascetti, F., Pulvirenti, L., Crapolicchio, R., Muñoz-Sabater, J., \& Mu??oz-Sabater, J. (2015). Analysis of ASCAT, SMOS, in-situ and land model soil moisture as a regionalized variable over Europe and North Africa. Remote Sensing of Environment, 170, 280 289. http://doi.org/10.1016/j.rse.2015.09.005

Piles, M., Camps, A., Vall-llossera, M., Corbella, I., Panciera, R., Rudiger, C., ... Walker, J. (2011). Downscaling SMOS-Derived Soil Moisture Using MODIS Visible/Infrared Data. IEEE Transactions on Geoscience and Remote Sensing, 49(9), 3156-3166. http://doi.org/10.1109/TGRS.2011.2120615

Piles, M., Petropoulos, G. P., Sánchez, N., González-Zamora, Á., \& Ireland, G. (2016). Towards improved spatio- temporal resolution soil moisture retrievals from the synergy of SMOS and MSG SEVIRI spaceborne observations. Remote Sensing of Environment. http://doi.org/10.1016/j.rse.2016.02.048

Rossato, L., De Jeu, R., Alvalá, R. C. D. S., \& Souza, S. (2011). Evaluation of soil moisture from satellite observations over South America. International Journal of Remote Sensing, 32(23), http://doi.org/10.1080/01431161.2010.532169

Scaini, A., Sanchez, N., Vicente-Serrano, S. M., \& MartinezFernandez, J. (2015). SMOS-derived soil moisture anomalies and drought indices: A comparative analysis using in situ measurements. Hydrological Processes, 29(3), 373-383. http://doi.org/10.1002/hyp.10150

Wanders, N., Karssenberg, D., Bierkens, M., Parinussa, R., de Jeu, R., van Dam, J., \& de Jong, S. (2012). Observation uncertainty of satellite soil moisture products determined with physically-based modeling. Remote Sensing of Environment, 127, 341-356. http://doi.org/10.1016/j.rse.2012.09.004

Yu, G., Di, L., \& Yang, W. (2008). Downscaling of global soil moisture using auxiliary data. In International Geoscience and Remote Sensing Symposium (IGARSS) (Vol. 3). http://doi.org/10.1109/IGARSS.2008.4779325 